\title{
Possibilidades no contexto de aulas remotas - avaliação da habilidade de leitura através de aplicativo de mensagens instantâneas
}

\author{
Blenda Priscila Alencar*
}

\section{Resumo}

Diante do cenário de isolamento social foi necessário a idealização de novos procedimentos para que ocorressem as aulas remotas objetivando a continuação e a construção da aprendizagem. Aproveitando o potencial da comunicação no universo digital e considerando a realidade do grupo pesquisado este trabalho teve como objetivo verificar a possibilidade da utilização do WhatsApp como recurso para a avaliação da habilidade leitora de alunos do $2^{\circ}$ ano do ensino fundamental. A pesquisa de cunho qualitativo adotou o aplicativo de mensagens instantâneas para o acompanhamento da aprendizagem e avaliação da leitura dos alunos. Foi utilizada como referência o quadro de sistematização de acompanhamento por aluno para a avaliação da leitura do Programa Aprendizagem na Idade Certa - MAISPAIC. Conclui-se que o aplicativo WhatsApp proporciona um ambiente digital de interação entre professor e aluno que possibilita $O$ acompanhamento da leitura dos educandos contribuindo para o processo de alfabetização e letramento.

Palavras-chave: Alfabetização, WhatsApp, Aulas Remotas.

* Prefeitura Municipal de Amontada. Pedagoga pela Universidade Estadual do Ceará - UECE. Psicopedagoga clínica e institucional. Especialista em docência do Ensino Superior. Professora efetiva da Prefeitura Municipal de Amontada. blenda.priiscylla@gmail.com 


\section{Possibilities in the context of remote classes - the use of instant messages application to evalua- te reading skills}

\section{Abstract}

In view of the social isolation scenario, it was necessary to devise new procedures for remote classes to take place, aiming at the continuation and construction of learning. Taking advantage of the potential of communication in the digital universe and considering the reality of the researched group, this work aimed to verify the possibility of using WhatsApp as a resource to assess the reading ability of 2nd year student's elementary school. A qualitative research adopted the instant messaging application to monitor students' learning and reading assessment. It was used as a reference to the system of systematization of monitoring by student to assess the reading of the Learning Program at the Right Age - MAISPAIC. Conclude if the WhatsApp application offers a digital environment of interaction between the teacher and the student that makes it possible to monitor the reading of students who contribute to the process of literacy and literacy.

Keywords: Literacy, WhatsApp, Remote Lessons.

\section{Posibilidades en el contexto de clases remotas - el uso de la aplicación de mensajes instantáneos para evaluar las destrezas de lectura}

\section{Resumen}

Ante el escenario de aislamiento social, fue necesario idear nuevos procedimientos para la realización de clases a distancia, con el objetivo de la continuación y construcción del aprendizaje. Aprovechando el potencial de la comunicación en el universo digital y considerando la realidad del grupo investigado, este trabajo tuvo como objetivo verificar la posibilidad de utilizar WhatsApp como recurso para evaluar la capacidad lectora de estudiantes de $2^{\circ}$ año escuela primaria. Una investigación cualitativa adoptó la aplicación de mensajería instantánea para monitorear la evaluación del aprendizaje y la lectura de los estudiantes. Se utilizó como referencia al sistema de sistematización de seguimiento por alumno para evaluar la lectura del Programa de Aprendizaje en la Edad Adecuada - MAISPAIC. Concluir si la aplicación WhatsApp ofrece un entorno digital de interacción entre el docente y el 
alumno que posibilita el seguimiento de la lectura de los alumnos que contribuyen al proceso de alfabetización y alfabetización.

Palabras clave: Alfabetización, WhatsApp, Lecciones remotas.

\section{Introdução}

O aplicativo multiplataforma, WhatsApp, permite a troca de mensagens de forma instantânea e gratuita, se inserindo no contexto educacional possibilitando novas formas de avaliação e contribuições para a prática docente. Por ser utilizado em aparelhos celulares, acessíveis para a maioria dos estudantes, o aplicativo mostra-se como aliado do processo de ensino e aprendizagem, podendo ser acessado em qualquer hora ou lugar. (MOREIRA \& SIMÕES, 2017)

As novas formas de comunicação, diversão e mídia, têm mudado a maneira de ser, pensar, agir e aprender de crianças, jovens e adultos, modificando radicalmente os conceitos de comportamento construídos (COSTA, 2009); uma nova alternativa de ensino capaz de unir tecnologia e educação, a Mobile Learning (aprendizagem com mobilidade), em que os dispositivos móveis são utilizados dentro e fora de sala de aula para auxiliar o processo de aprendizagem. (OLIVEIRA et al., 2014).

Em busca de garantir amplas oportunidades para que os alunos se apropriem do sistema de escrita alfabética, desenvolvimento de habilidades de leitura e escrita assim como práticas diversificadas de letramento, a Base Nacional Curricular Comum estabelece que nos dois primeiros anos do ensino fundamental o foco da ação pedagógica deve ser a alfabetização.

Nesse processo, é preciso que os estudantes conheçam o alfabeto e a mecânica da escrita/leitura - processos que visam a que alguém (se) torne alfabetizado, ou seja, consiga "codificar e decodificar" os sons da língua (fonemas) em material gráfico (grafemas ou letras), o que envolve o desenvolvimento de uma consciência fonológica (dos fonemas do português do Brasil e de sua organização em segmentos sonoros maiores como sílabas e palavras) e o conhecimento do alfabeto do português do Brasil em seus vários formatos (letras imprensa e cursiva, maiúsculas e minúsculas), além do estabelecimento de relações grafofônicas entre esses dois sistemas de materialização da língua. (BRASIL, 2017, p.90) 
O Programa de Aprendizagem na Idade Certa através da Proposta Didática para Alfabetizar Letrando busca um processo de alfabetização unindo-se ao letramento, pois concebe que é desta forma que se possibilita ao aluno aprender a Língua Portuguesa enquanto descobre e usufrui dos significados das práticas socioculturais de oralidade, leitura e escrita; a apropriação do sistema de escrita alfabética e ortográfica no uso das práticas socioculturais e nos procedimentos da linguagem envolvidos.

Segundo a referida proposta, no momento em que o professor assimila a dimensão da alfabetização e do letramento de modo indissociável, os alunos aprendem a ler e escrever com melhor qualidade. Magda Soares declara que:

[...] a alfabetização se desenvolve no contexto de e por meio de práticas sociais de leitura e escrita, isto é, através de atividades de letramento, e este, por sua vez, só pode desenvolver- se no contexto da e por meio da aprendizagem das relações fonema-grafema, isto é, em dependência da alfabetização. (SOARES, 2003, p.13)

Partindo dessa premissa, o Programa de Aprendizagem na Idade Certa almeja que ao final do $2^{\circ}$ ano, as crianças sejam capazes de ler com autonomia textos curtos e devido à complexidade deste processo é necessário que exista um acompanhamento específico dos professores desta etapa da alfabetização dos alunos.

A avaliação contínua da leitura dos alunos nesta etapa é de suma importância para a orientação do trabalho do professor em busca de contribuir com as necessidades específicas de cada educando, assim como o direcionamento da metodologia a ser trabalhada em sala de aula. Entretanto, diante do cenário de isolamento social, foi necessário a idealização de novos procedimentos para a análise de nível de leitura dos alunos.

Ao aproveitar o potencial de comunicação do universo digital, a escola pode instituir novos modos de promover a aprendizagem, a interação e o compartilhamento de significados entre professores e estudantes (BRASIL, 2017). A aquisição de conheci- 
mento, assim como a avaliação do processo pode acontecer virtualmente, na medida em que ocorra a ação comunicativa entre professor-aluno e aluno-aluno, há o compartilhamento de informações, a formulação de ideias e a resolução de problemas.

Há que se considerar, ainda, que a cultura digital tem promovido mudanças sociais significativas nas sociedades contemporâneas. Em decorrência do avanço e da multiplicação das tecnologias de informação e comunicação e do crescente acesso a elas pela maior disponibilidade de computadores, telefones celulares, tablets e afins, os estudantes estão dinamicamente inseridos nessa cultura, não somente como consumidores. Os jovens têm se engajado cada vez mais como protagonistas da cultura digital, envolvendo-se diretamente em novas formas de interação multimidiática e multimodal e de atuação social em rede, que se realizam de modo cada vez mais ágil (BRASIL, 2017, p.61).

A pesquisa da Nova Escola (2020), aponta que as plataformas mais utilizadas pelos professores para contatar as famílias e alunos são, nessa ordem, o WhatsApp, Facebook e por último o portal da instituição. $\mathrm{O}$ aplicativo WhatsApp pode ser uma ferramenta importante de debates, aulas interativas e de produção intelectual dos estudantes (MOREIRA \& SIMOES, 2017).

Contudo, o uso de aplicativos de mensagens instantâneas para os anos iniciais do ensino fundamental não está totalmente compreendido, e em um momento onde as aulas presenciais não podem ocorrer é necessário a busca para compreender as ferramentas que estão disponíveis e suas funcionalidades para a educação. Portanto, o objetivo deste trabalho é verificar a utilização do WhatsApp como recurso para a avaliação da habilidade leitora de alunos do $2^{\circ}$ ano do ensino fundamental.

\section{Metodologia}

Trata-se de um trabalho de natureza qualitativa que segundo Thiollent (1986) é basicamente aquela que busca entender um fenômeno específico em profundidade. A vertente qualitativa da pesquisa trabalha com descrições, comparações e interpretações, contrariamente a estatísticas, regras e outras generalizações. 
O trabalho contemplou o escopo de pesquisa exploratória na medida em que propõe explorar textos, recursos e ferramentas metodológicas buscando proporcionar uma visão geral, de tipo aproximativo, acerca de determinado fato (GIL, 2009, p. 27).

O procedimento metodológico deu-se em uma escola pública municipal de Amontada- Ceará em uma turma de $2^{\circ}$ ano do ensino fundamental com dezessete alunos durante o período letivo de 2020.

A pesquisa iniciou com um levantamento sobre as tecnologias digitais e o acesso à internet disponíveis aos estudantes da turma e a partir do resultado foi possível escolher que aparato seria utilizado para continuação das aulas no contexto remoto.

Desta maneira, a plataforma WhatsApp foi escolhida para o acompanhamento da aprendizagem e avaliação da leitura dos alunos. Foi utilizado como referência o quadro de sistematização de acompanhamento por aluno para a avaliação da leitura do Programa Aprendizagem na Idade Certa - MAISPAIC que se baseia nos Direitos de Aprendizagens propostos pelo MEC/PNAIC e, de modo especial, na Proposta Curricular de Língua Portuguesa e na Proposta Curricular de Matemática do $1^{\circ}$ ao $5^{\circ}$ ano do PAIC/ Estado do Ceará (2014).

A avaliação inicial ocorreu de forma presencial em fevereiro, pois os alunos partícipes da pesquisa ainda estavam no ambiente escolar presencial iniciando o ano letivo de 2020. As avaliações conseguintes ocorreram de maneira remota nos meses de abril, junho e agosto.

\section{Resultados e discussão}

Muitos desafios surgiram devido o ensino remoto ter iniciado de forma emergencial em todas as escolas do país. Uma das maiores preocupações foi a continuidade no processo de alfabetização, por ser considerado uma etapa muito importante no processo educativo e que necessita de um acompanhamento específico pela escola.

O Parecer CNE/CP n ${ }^{\circ}$ 5, de 28 de abril de 2020, destaca como ponto chave, a discussão sobre reorganizar as atividades edu- 
cacionais por conta da pandemia objetivando minimizar os impactos das medidas de isolamento social na aprendizagem dos estudantes, considerando a longa duração da suspensão de atividades educacionais presenciais.

Gabriel (2013) aponta que a evolução das tecnologias digitais de informação e comunicação tem transformado profundamente a sociedade em todas as suas dimensões, inclusive a educação. Sendo a alternativa mais cabível em um momento que a educação deveria ocorrer frente a um distanciamento social.

Devido a importância da etapa de alfabetização, é fundamental o acompanhamento dos alunos neste processo. Por esse motivo, foi realizado um levantamento inicial com uma turma de $2^{\circ}$ ano do ensino fundamental sobre a maneira que os alunos teriam acesso as aulas remotas. Foi verificado que 15 alunos usam smartphones dos pais ou familiares próximos e internet de uma companhia de telefonia móvel, um tem acesso a smartphone, mas não tem acesso à internet e um não tem acesso a nenhum dispositivo tecnológico.

É importante ressaltar que esta realidade não é exclusiva desta sala de aula. De acordo com o IBGE (2020) 25,3\% dos brasileiros não possuem acesso à internet, considerando espaços urbanos e rurais, no caso desse último, 53,5\% das pessoas não possuem acesso.

Usando como ponto de partida o diagnóstico de leitura inicial feito em fevereiro de 2020, antes da suspensão das aulas presenciais, a turma apresentava cinco alunos não leitores, quatro alunos que conseguiam ler palavras, três alunos que liam frases, três alunos que liam texto sem fluência e dois alunos que liam textos com fluência.

De acordo com a BNCC cabe ao componente da Língua Portuguesa proporcionar aos estudantes experiências que contribuam para a ampliação dos letramentos, de forma a possibilitar a participação significativa e crítica nas diversas práticas sociais constituídas pela oralidade, pela escrita e por outras linguagens (BRASIL, 2017).

Frente a realidade dos educandos iniciamos a utilização do aplicativo WhatsApp como o recurso para as aulas remotas com 
textos, atividades, dinâmicas, contação de histórias e diversas metodologias, buscando uma ação pedagógica coerente e significativa.

Totti et al. (2011) aponta que com avanço dos dispositivos móveis, eles representam um caminho alternativo para a educação, mas não em direção contrária aos já existentes, por isso foi utilizado e adaptado o quadro de sistematização de acompanhamento do aluno por etapa para a avaliação da leitura do Programa Aprendizagem na Idade Certa para um diagnóstico contínuo e somativo através de atividades, ligações, áudios e principalmente, vídeos dos alunos enviados por WhatsApp.

Como já mencionado anteriormente, através das referências do quadro de sistematização de acompanhamento por aluno para a avaliação da leitura do MAISPAIC, os níveis utilizados para a avaliação da leitura foram: Não leitor, leitor de palavras, leitor de frases, leitor de texto sem fluência e leitor de texto com fluência.

Os resultados obtidos nos diagnósticos de leitura foram sumarizados no gráfico 1 abaixo.

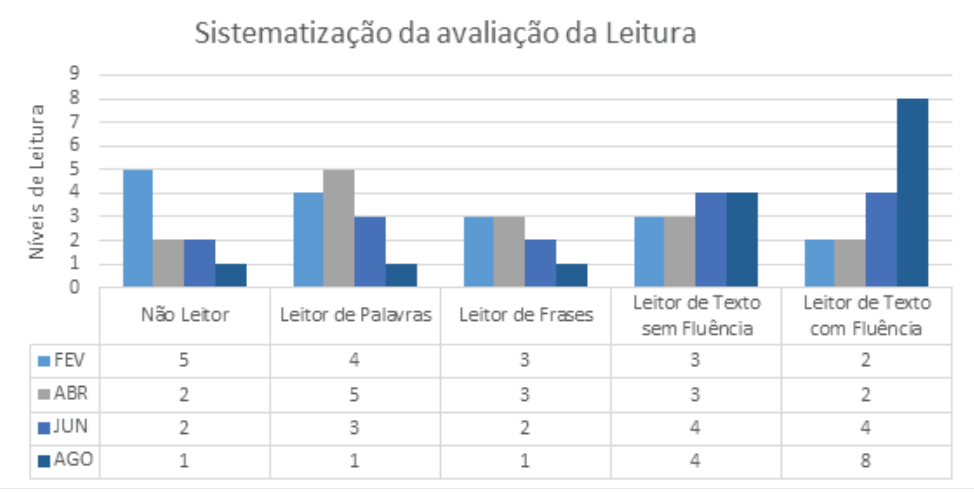

Gráfico 1 - Avaliação e sistematização da leitura dos alunos do $2^{\circ}$ ano entre os meses de fevereiro a agosto

Fonte: Elaborado pela autora (2020).

É notório que as mudanças mais expressivas na leitura apresentadas pelos alunos de fevereiro a abril ocorreram no nível de não 
leitor e leitor de palavras, onde alunos iniciaram seu processo de leitura de palavras e frases. Destacamos que no início de março ocorreu a paralisação das atividades presenciais nas escolas e que houve um período de incertezas e espera até o início das atividades remotas.

Em junho, algumas alterações foram identificadas. Dois alunos apresentaram leituras de textos curtos com fluência e interpretação, assim, totalizando quatro alunos neste nível. Quatro alunos estavam lendo textos curtos, porém sem fluência, dois lendo frases, três em leituras de palavras e dois ainda se encontravam não leitores.

Foi identificado que dois alunos da turma não estavam conseguindo participar das atividades remotas devido à falta de acesso dos estudantes à internet. Moreira \& Kramer (2007) apontam que as tecnologias não asseguram o desaparecimento das desigualdades econômicas e divergências das cidades. Sarlo (2014) em seus estudos, também discute sobre a parcela dos usuários da cidade que são excluídos da modernização. Barton \& Lee (2015) destacam que ainda há muitos problemas de acesso e diferenças entre pessoas e grupos.

No mês de agosto, os dados apresentados demonstravam oito leitores de texto com fluência, quatro leitores de textos curtos sem fluência, um leitor de frases, um leitor de palavras e um aluno não-leitor. Um quadro diferente do demonstrado ao início, fazendo com que acreditemos que houve aprendizagem neste período atípico, mesmo ainda não tendo sido concluído o ano letivo.

Com a popularização dos dispositivos móveis e das conexões de dados móveis houve um maior acesso no uso de tecnologias móveis e este fator nos auxiliou neste período de isolamento social para que as crianças não ficassem sem acompanhamento escolar. Foi possível analisar evoluções em suas leituras e contribuir para a aprendizagem mesmo que a distância.

Os alunos que não tinham acesso à internet receberam atividades impressas e visitas domiciliares da professora, seguindo todas as normas indicadas pelos órgãos de saúde. Este aspecto apresenta-se como relevante a ser discutido posteriormente e considerado pelas políticas públicas, pois a falta de conectividade neste momen- 
to implica em mais uma forma de exclusão, e talvez uma das mais cruéis, a exclusão escolar.

Diante de tantos desafios que englobam este momento diferenciado no processo escolar, é compreensível que nem todos os alunos obtiveram a evolução considerada ideal, tendo em vista que as atividades diárias e o maior contato do professor com o aluno são pontos fundamentais nesse processo.

Estamos cientes de que as Tecnologias da Informação e Comunicação não devem ser entendidas como sinônimo de educação escolar de qualidade, mas acreditamos que todos os recursos possíveis e existentes podem ser empregados para propiciar formação humana, excedendo a ideia de uso de ferramentas tecnológicas apenas como demanda social ou de mercado de trabalho.

Como afirma Moreira \& Simões (2017):

É comunicando virtualmente, mediante a troca de mensagens, que a aquisição do conhecimento pode acontecer continuamente. $\mathrm{Na}$ medida em que possibilita a ação comunicativa entre professor-aluno e alunoaluno, há o compartilhamento de informações, a formulação de ideias e a resolução de problemas. O aplicativo WhatsApp pode ser uma ferramenta importante de debates, aulas interativas e de produção intelectual dos estudantes (MOREIRA; SIMOES, 2017, p.28).

Nesse sentido, compreendemos que, uma vez que professores e alunos trabalham juntos, ocorre a construção de saberes, resultando em benefícios não apenas a comunidade escolar local, mas toda a sociedade na qual estão inseridos e podem ser agentes de mudanças (COSTA \& LOPES, 2016).

\section{Considerações finais}

A tecnologia no ensino e a inclusão de recursos tecnológicos já são uma realidade em muitas escolas, porém, diante dos desafios de lecionar em um período de isolamento social, as instituições de educação migraram rapidamente para as TIC's a fim de auxiliar estudantes e professores na continuação e construção do conhecimento. 
O uso do WhatsApp em espaços educacionais ainda precisa ser discutido pois é notório os obstáculos de ordem tecnológica, econômica e social que muitas regiões no país perpassam. Contudo, conforme mostrou a pesquisa é uma ferramenta que pode ser utilizada para o acompanhamento e avaliação do desenvolvimento dos educandos.

De acordo com o Plano Nacional de Alfabetização, a leitura é um meio propício para ampliar o vocabulário, enriquecer a expressão oral e escrita, despertar a sensibilidade estética e o gosto pelos livros, por isso se deve pôr todo o cuidado e o aplicativo WhatsApp contribuiu significativamente para o trabalho docente tanto em oferecer possibilidade de interação entre professor e aluno fora do ambiente escolar como em relação ao acompanhamento da leitura dos educandos, essencial na etapa de alfabetização.

Entretanto, conforme alertam Barton \& Lee (2015), a tecnologia por si só não provoca mudanças na vida dos usuários. O resultado positivo somente foi alcançado devido a um planejamento pedagógico de acordo com a realidade dos educandos e participação ativa das famílias no processo.

Considerando a pouca disseminação do aplicativo WhatsApp como uma ferramenta educacional, e sendo uma tecnologia relativamente jovem é necessário ampliar os estudos na busca de expandir o potencial pedagógico que este recurso pode oferecer, assim como, na resolução dos desafios de possibilitar acesso para todos.

\section{Referências}

BRASIL. Base Nacional Comum Curricular (BNCC). Educação é a Base. Brasília, MEC/CONSED/UNDIME, 2017.

BRASIL. Ministério da Educação. Secretaria de Alfabetização. PNA Política Nacional de Alfabetização/Secretaria de Alfabetização. - Brasília: MEC, SEALF, 2019. 54 p.

BRASIL. Ministério da Educação. Conselho Nacional de Educação. Parecer $\mathrm{CNE} / \mathrm{CP}$ n$^{\circ}$ 5, de 28 de abril de 2020. Reorganização do Calendário Escolar e da possibilidade de cômputo de atividades não presenciais para fins de cum- 
primento da carga horária mínima anual, em razão da Pandemia da COVID-19. Brasília. 2020

BARTON, D.; LEE C. Linguagem Online - Textos e Práticas Digitais. São Paulo: Parábola Editorial, 2015.

CEARÁ. Secretaria da Educação. Proposta didática para Alfabetizar Letrando do $2^{\mathbf{o}}$ ano: caderno do professor $1^{\mathrm{a}}$ e $2^{\mathrm{a}}$ etapa/ Secretaria da Educação - Fortaleza: SEDUC,2018.

COSTA, M. V. A educação na cultura da mídia e do consumo. Rio de Janeiro: Lamparina, v.2, 2009.

COSTA. D.M.; LOPES. J. R. “Quem Forma Se Forma E Reforma Ao Formar”: Uma Discussão Sobre As Tics Na Formação De Professores. In: Tecnologia, Sociedade e Educação na Era Digital. VILAÇA.M.L.C.; ARAÚJO.E.V.F.Org. Unigranrio. Rio de Janeiro.2016.

GABRIEL, M. Educ@r: a (r)evolução digital na educação. São Paulo: Saraiva, 2013.

GIL, A. C. Métodos e técnicas de pesquisa social. 6a .ed. São Paulo: Atlas, 2009.

IBGE. Um em cada 4 brasileiros não tem acesso à internet, mostra pesquisa. Agencia IBGE de notícias. 2020.

MOREIRA, M. L.; SIMÕES, A. S. M. O uso do WhatsApp como ferramenta pedagógica no ensino de Química. ACTIO: Docência em Ciências.v.2. n.3.2017

MOREIRA, A. F. B., KRAMER, S. Contemporaneidade, Educação e Tecnologia. Educ. Soc. Campinas, Vol. 28, n. 100, Especial, 2007, p. 103-157.

OLIVEIRA, E. et al. Estratégias de uso do WhatsApp como um ambiente virtual de aprendizagem em um curso de formação de professores e tutores. In: Simpósio Internacional De Educação A Distância - SIED, 2.; Encontro De Pesquisadores Em Educação A Distância - ENPED, 2., 2014, São Carlos. Anais... São Carlos: [s.n.], 2014. p. 1-15.

SANTOS, V. A situação dos professores no Brasil durante a pandemia. Nova escola.2020. Disponível em: $<$ https://novaescola.producao.s3.amazonaws.com/ MEWKNnJz3TJ8kKd7UhRpCuVcR95vP4VAEk83JtQSe4cferz85NnUvehrccET/ne-pesquisa-professor-final-1.pdf $>$ Acesso em 20 de ago. de 2020 
SARLO, B. A cidade vista: mercadorias e cultura urbana. São Paulo: Editora WMF Martins Fontes, 2014.

SOARES, M. Letramento e alfabetização: as muitas facetas (texto apresentado no GT de alfabetização). Anais. 26ª Reunião da ANPEd. Poços de Caldas: 2003

THIOLlENT, M. 1947 - Metodologia da Pesquisa-Ação. São Paulo. Cortez: Autores ASSOCIADOS, 1986.

TOTTI, A. R.; MOREIRA, S. P. T.; SOUZA, W. G.; GOMES, C. M-learning: Possibilidades Para A Educação A Distância. In: $17^{\circ}$ Congresso Internacional ABED de Educação a Distância, 2011, Manaus. Anais. A Grande Conversação: Diferentes Formas de Aprender, Conteúdos Variados e Tecnologias Diferenciadas - Interação com Diversidade, 2011.

Submetido em: 8-11-2020

Aceito em: 27-7-2021 